admittedly the largest-that its annual levy, at a rate of 2.5 per cent of industrial turnover, will amount to $£ 75$ million-a sum not very different from the $£ 130$ million spent on British universities in a year.

In the administration of this levy and the compensating grants to companies, the boards must necessarily act as judges of what is good practice. But how do they know what is good? The engineering board has taken a step in the right direction by advertising its willingness to make grants for "research projects directed towards improving the effectiveness of training". It will be interesting to see how soon such work can provide an objective evaluation of the benefits (or otherwise) of the industrial training, which has necessarily grown up in a somewhat empirical fashion.

\section{Ornithology in 1966}

Dr. D. W. SNow, of the British Trust for Ornithology, writes: "The fourteenth International Ornithological Congress, which took place at Oxford during July 24-30, was the largest ever held, with some 900 members from forty-four countries. The 130 papers presented were ample proof that research in birds continues to make important advances in such diverse fields as systematics, behaviour, reproductive physiology and population dynamies. This has indeed been so for the past 25 years, as shown by such books as Mayr's Systematics and the Origin of Species, Tinbergen's Study of Instinct, and Lack's Natural Regulation of Animal Numbers, which draw more of their examples from birds than from any other group of animals. But the Congress also reflected some newer trends in ornithological research.

"Most strikingly, ethology, in the restricted sense of the study of the causal analysis or motivation of behaviour, was not represented at all. Instead, most of the papers on behaviour dealt with the development and function of song and other vocalizations, a field in which rapid advances have been made in recent years thanks to the sound spectrograph. One paper in particular, by Prof. Niko Tinbergen, Secretary General of the Congress, stressed the adaptive significance of specific behaviour patterns in the context of the whole ecology of the species, an aspect of behaviour which has been rather neglected.

"Evolutionary studies also showed a change of emphasis. Studies of geographical variation and speciation were rather few; in birds this is well-worn ground and the main established principles are not likely to alter. Instead, there were several papers dealing with evolution at the family level or higher, among them an account of Prof. Charles Sibley's studies of avian haemoglobins and egg-white proteins. These studies are likely to clear up many of the debated problems of the relationships between the various orders of birds, for which the evidence from morphology is equivocal.

"The paper by the President of the Congress, Dr. David Lack, opened the eyes of many ornithologists to the wider significance of aspects of bird behaviour and ecology which have often been studied in isolation from each other. Entitled "Inter-relationships in Breeding Adaptations", it aimed to show that the type of nesting dispersion (colonial or widely spaced, for example), the nature of the nest site, the incubation and fledging periods, the type of young (whether nidicolous or nidifugous), the ability of the parent birds to defend their nest, and food and feeding habits are all inter-connected. None of them can be fully understood without reference to the others. Dr. Lack drew his examples from sea birds because they have been the subject of many detailed studies in recent years, but the same principles probably apply to all. (Prof. Tinbergen's paper, already mentioned, was planned jointly with Dr. Lack's and dealt with essentially the same theme from the point of view of behaviour.) This approach is likely to prove fruitful, and will make evolutionary sense of many facts which now seem merely isolated details.

"Several contributions at the Congress dealt with new techniques of radio-telemetry which will in coming years undoubtedly lead to great advances in the study of populations and migration and orientation. It is already possible to record for each of fifty-two birds simultaneously one location every $45 \mathrm{sec}$, and to plot the results automatically on maps. The possibilities are boundless, and more will undoubtedly be heard of them at the next Congress four years hence."

\section{More River Meandering}

A FURTHER development in the theory of river meandering has now appeared as Professional Paper 422- $\mathrm{H}$ of the United States Geological Survey. The paper is credited to Dr. Luna Leopold and Mr. W. B. Langbein, respectively the chief hydrologist and a research hydrologist with the U.S. Geological Survey, both of whom have been closely associated with the theory of river meandering for the past decade, particularly since Dr. H. von Schelling showed, in 1951, that the meandering of rivers is really a random walk problem ${ }^{1,2}$. By field studies of actual rivers, it has now been shown that there is a negative correlation between the meandering of rivers and certain other characteristics of the bed of a river which dissipate energy. Briefly, the studies have confirmed what successful fishermen have known for centuries--the more sinuous a river, the smoother the bed and the more uniform the velocity of flow.

The starting point for Von Schelling's theory is the hypothesis that the probability of a river deviating by an angle $d \phi$ from its previous direction in a distance $\mathrm{d} s$ is best represented by a Gaussian distribution. This leads to the conclusion that the shapes of rivers should be determined by the condition that:

$$
\Sigma(\Delta \phi)^{2} / \Delta s
$$

should be a minimum. With suitable approximations, this boils down to the assertion that the shape of a meandering river can be obtained from an equation:

$$
\phi=\omega \sin 2 \pi(s / M)
$$

which specifies the deviation of the river $(\phi)$ from the direct path at all distances $s$ along the loop the total length of which is $M$. The constant $\omega$ is a measure of sinuosity. Observation in the past decade has shown that a great many meandering rivers can be adequately accounted for by such a formula.

What Leopold and Langbein have now done is to obtain a correlation between the sinuosity of a river and the variances of depth, velocity, slope and shear, and also with a parameter which is a measure of frictional forces at the bed of the river. They have 